\title{
Meu filho sob uma luz: a assistência de enfermagem em puérperas de neonatos sob fototerapia
}

\author{
Ana Paula Lopes*, Bruna Coutinho da Silva*, Célia Cristina Vasconcellos*, Gabrielle Souza de Carvalho*, \\ Pâmella da Costa Reis*, Fernanda Garcia Bezerra Góes**, Diego Pereira Rodrigues***
}

*Enfermeiras, graduadas no Centro Universitário Plinio Leite (UNIPLI), Niterói/RJ, **Enfermeira do IPPMG/UFRJ,

Doutoranda em Enfermagem da Escola de Enfermagem Anna Nery (EEAN) da Universidade Federal do Rio de Janeiro (UFRJ), Rio de Janeiro, ***Enfermeiro, Mestrando em Ciências do Cuidado da Saúde da Escola de Enfermagem Aurora de Afonso Costa (EEAAC) da Universidade Federal Fluminense (UFF), Rio de Janeiro

\section{Resumo}

Este estudo tem como objetivo descrever a assistência de enfermagem junto às mães de neonato com hiperbilirrubinemia em Unidade de Terapia Intensiva Neonatal (UTIN). A metodologia utilizada foi revisão integrativa de literatura com coleta de dados nas bases eletrônicas Literatura Latino-Americana e do Caribe (Lilacs), Scientific Eletronic Library Online (Scielo) e Base de Dados de Enfermagem (Bdenf), das quais foram selecionados 9 artigos para análise. Os resultados apontam que as experiências vivenciadas pelas mães de recém-nascidos com hiperbilirrubinemia sob terapêutica de fototerapia são assustadoras, pois o ambiente desconhecido, seu filho sob uma luz intensa e com cuidados especiais de toda a equipe de saúde da UTIN favorece para esse quadro. Isso é agravado pela falta de informação, comunicação e esclarecimento à mãe por parte dos profissionais, especificamente o enfermeiro. Observou-se uma necessidade de uma assistência integral, individual e humanizada, focando não apenas o cuidado, mas também o sofrimento vivenciado pelas mães. É fundamental estabelecer essa comunicação da equipe de saúde com a mãe através de uma análise clara e sucinta, oferecendo um suporte a essa mãe que se encontra com uma gama de sentimentos. Apontamos que essas práticas não vivenciadas devem ser desenvolvidas e devemos repensar os ensinamentos e orientaçôes para que possamos, finalmente, assumir autenticamente os cuidados de enfermagem ao binômio mãe-filho no sentido de proporcionar melhor qualidade da assistência.

Palavras-chave: hiperbilirrubinemia, fototerapia e Enfermagem.

\section{Abstract}

\section{My son under lights: nursing care provided to mothers of newborns under phototherapy}

The aim of this study was to describe the nursing care provided to mothers of newborns affected by hyperbilirubinemia in Neonatal Intensive Care Unit (NICU). The methodology chosen was the integrative literature review, and data was collected from Latin America Literature and Caribbean (Lilacs), Scientific Eletronic Library Online (Scielo), Database 
Search Nursing (Bdenf), however only 9 studies were selected. The results point out that mothers whose babies develop hyperbilirubinemia and need to stay under phototherapy experience terrifying moments. The unknown environment and their child under intensive lights with special health care needs from NICU staff corroborate to this feeling. The situation becomes worse since the health professionals, especially nurses, do not give information and clarification about this therapy. Moreover, it was observed that an integral, individual and humanized care is needed, because the focus should not be only on nursing care, but also in the suffering that mothers are going through. It is essential that the communication between health professionals and mothers be done through a clear and brief analysis, since these mothers are going through a difficult moment. Besides, we must rethink our teaching and orientation so as to assume authentically the nursing care to the binomial mother-child in order to provide a better nursing care.

Key-words: hyperbilirubinemia, phototherapy, nursing.

\section{Resumen}

\section{Mi hijo bajo una luz: atención de enfermería a madres de recién nacidos bajo fototerapia}

Este estudio tiene como objetivo describir la atención de enfermería prestada a las madres de recién nacido con hiperbilirrubinemia en Unidad de Cuidados Intensivos Neonatal (UCIN). La metodología utilizada fue la revisión integradora de literatura con coleta de datos en las bases electrónicas Literatura Latinoamericana y del Caribe en Ciencias de la Salud (Lilacs), Scientific Eletronic Library Online (Scielo), Base de datos de Enfermería (Bdenf). Nueve estudios fueron seleccionados para el análisis. Los resultados apuntan que las experiencias vividas por las madres de recién nacidos con hiperbilirrubinemia bajo fototerapia son aterradoras. El ambiente desconocido, el hijo bajo una luz intensa y con cuidados especiales de todo el equipo de salud de la UCIN promueve un sentimiento aterrorizador. La falta de información, comunicación y esclarecimientos a la madre por parte de los profesionales, especialmente el enfermero, contribuyen a agravar la situación. Se observó una necesidad de una atención integral, individual y humanizada, centrada no sólo en el cuidado, sino también en el sufrimiento vivenciado por las madres. Es fundamental establecer la comunicación entre el equipo de salud y la madre en forma clara y sucinta, ofreciendo apoyo a esa madre que se encuentra en momentos difíciles. Apuntamos que esas prácticas no vivenciadas deben ser desarrolladas y debemos repensar las enseñanzas y orientaciones para que podamos, finalmente, asumir auténticamente los cuidados de enfermería al binomio madre-hijo en el sentido de proporcionar mejor atención de calidad.

Palabras-clave: hiperbilirrubinemia, fototerapia, Enfermería.

\section{Introdução}

A hiperbilirrubinemia é uma condição em que a bilirrubina está com seus níveis elevados na corrente sanguínea do recém-nascido $(\mathrm{RN})$, sendo caracterizada pelo aparecimento de pigmentação amarelada da pele, mucosa, esclerótica, que denominamos icterícia. Sua causa está relacionada ao acúmulo de bilirrubina não conjugada na corrente sanguínea, podendo ser fisiológica ou patológica [1].

Diversos fatores podem desencadear esse desequilíbrio no recém-nascido como a prematuridade, aleitamento materno tardio, anormalidades hepáticas, biliares ou metabólicas, produçáo excessiva de bilirrubina, incapacidade do fígado de secretar bilirrubina conjugada, diabetes materna, uso materno de diazepam, salicilatos, sulfonamidas ou ocitocina, dentre outros [2].

Dentro desse contexto, a icterícia fisiológica é definida como uma hiperbilirrubinemia não conju- gada que se manifesta em recém-natos a termo no $3^{\circ}$ dia ou logo após e desaparece antes do $10^{\circ}$ dia, sendo provocada pelo aumento da carga de bilirrubina e de uma deficiente conjugação e excreção hepática da bilirrubina. Já a icterícia patológica ocorre nas primeiras 24 horas após o nascimento, a qual é determinada pelo aumento dos níveis de bilirrubina sérica no sangue, que se encontram acima de $15 \mathrm{mg} / \mathrm{dl}(\mathrm{RN}$ a termo) ou $10 \mathrm{mg} / \mathrm{dl}$ (RN prematuros) [2,3].

Devemos destacar que a presença de bilirrubina sérica de aproximadamente $20 \mathrm{mg} / \mathrm{dl}$ por um longo período na corrente sanguínea do RN pode levar a encefalopatia bilirrubínica ou doença de kernicterus. Nos casos leves de toxicidade da bilirrubina os neonatos que conseguem sobreviver podem apresentar dificuldade de aprendizado, entretanto, nos casos graves pode haver retardo mental, perda de audição e disfunçôes motoras [4].

Nesse sentido, é necessário agir em prol da saúde do RN, implementando a terapêutica neces- 
sária para a diminuição dos níveis de bilirrubina no sangue e combatendo a hiperbilirrubinemia. Desse modo, pode-se realizar a fototerapia, que envolve a aplicação de luz fluorescente, favorecendo a excreção da bilirrubina através da fotoisomerização, a qual altera a estrutura da bilirrubina para uma forma solúvel, que é mais facilmente excretada. Outro modo de terapia contra a hiperbilirrubinemia é a exsanguineotransfusão, na qual o sangue do RN é retirado em pequenas quantidades (em geral 5 a $10 \mathrm{ml}$ ) e substituído com sangue compatível, cuja finalidade é de remover os eritrócitos sensibilizados, diminuir o nível sérico de bilirrubina, corrigir anemia e evitar insuficiência cardíaca, sendo utilizado quando a fototerapia náo obteve o resultado esperado para a terapêutica [2].

Percebe-se que para a realização da fototerapia é necessário programar alguns cuidados. Então, é preciso que a enfermagem exerça e avalie os seus cuidados agindo nesta perspectiva e promovendo a saúde do $\mathrm{RN}$, como posicionamento da fonte luminosa, proteçáo dos olhos e gônadas, mudança de decúbito, avaliação do estado de hidratação cutânea, balanço hídrico, temperatura e eliminações fisiológicas [3].

A eficácia do cuidado de enfermagem para os $\mathrm{RN}$ com hiperbilirrubinemia é determinada pela reavaliaçáo contínua dos cuidados com base na observação dos resultados esperados como a coloração da pele, rever os achados laboratoriais, observar sinais de distúrbios neurológicos, verificar a coloração das vendas oculares, observar a pele quanto aos sinais de desidratação e temperatura durante $o$ tratamento da fototerapia.

Sabemos que as principais metas de uma Unidade de Terapia Intensiva Neonatal (UTIN) são a redução da morbidade e da mortalidade perinatais e a busca de sobrevivência do recém-nascido nas melhores condiçóes possíveis. Em virtude das características destes locais, os profissionais de saúde que ali desenvolvem suas atividades se encontram quase sempre muito envolvidos em procedimentos de alta complexidade. Diante disso, podem ser comprometidas as relaçóes interpessoais, especificamente no caso de máes de neonatos com hiperbilirrubinemia sob fototerapia.

Nesta perspectiva, ao adentrarem a primeira vez na UTIN, a mãe pode ser tomada por uma gama de sentimentos diante de um ambiente estranho e assustador. Neste, quase sempre, a comunicação é falha ou nem se quer existe, e as informaçóes acerca do estado de saúde do seu filho, bem como de todo o aparato tecnológico que o cerca, na grande maioria, não acontecem ou deixam a desejar [5].

$\mathrm{Na}$ nossa concepção, este comprometimento influi decisivamente no relacionamento profissional-família. Portanto, o grande desafio enfrentado nos dias de hoje pela equipe de saúde das UTIN é a prática da humanização da assistência, pois a tecnologia cada vez mais se supera.

Dessa forma, buscando analisar a perspectiva da humanização da assistência, o presente estudo teve como objetivo descrever a assistência de enfermagem junto às mães de neonato com hiperbilirrubinemia em UTI neonatal a partir da literatura científica.

Além de promover o maior contato máe-filho, é de extrema importância promover contato entre a equipe de enfermagem e a família do neonato, pois é nesse momento que a família pode sanar todas as dúvidas em relação à patologia de seus filhos. E cabe aos enfermeiros ser humanizados e ter a consciência de quanto é importante essa assistência.

A mudança desse paradigma da saúde é necessária, entáo pretendemos com o estudo contribuir junto aos profissionais da área da saúde e futuros enfermeiros levando à reflexáo da equipe de enfermagem quanto à importância da promoção do maior contato das máes com os neonatos durante o tratamento não só da hiperbilirrubinemia, mas de outras patologias em UTIN.

\section{Material e métodos}

Trata-se de uma Revisão integrativa realizada nas seguintes bases de dados: Literatura Latino-Americana e do Caribe (Lilacs), Scientific Eletronic Library Online (Scielo) e Base de Dados de Enfermagem (Bdenf), realizada no período de outubro a novembro de 2011.

A Revisão Integrativa é um método de revisão mais amplo, pois permite incluir literatura teórica e empírica, bem como estudos com diferentes abordagens metodológicas [6]. E, a abordagem metodológica utilizada para análise dos dados foi qualitativa, que são informaçóes obtidas que não podem ser quantificáveis e os dados são analisados intuitivamente [7].

Os estudos incluídos na revisão são analisados de forma sistemática em relação aos seus objetivos, materiais e métodos, permitindo que o leitor analise o conhecimento pré-existente sobre o tema investigado [6]. 
A Revisão Integrativa se divide em seis etapas que foram utilizadas nesta pesquisa, a primeira é a identificação do tema e elaboração da Questão Norteadora, que foi a seguinte:

Qual a assistência de enfermagem junto às mães dos neonatos com hiperbilirrubinemia em UTI neonatal?

A segunda etapa foi o estabelecimento de critérios de inclusão, que foram estes: estudos publicados nos últimos 10 anos; textos em Português, artigos científicos que conceituem Hiperbilirrubinemia, Fototerapia, Enfermagem. E critérios de exclusão: trabalhos científicos que não atendessem a questão do estudo. Ainda nesta etapa foi realizada a busca de amostragem na literatura e estabelecimento dos descritores a serem utilizados, que nesta pesquisa foram: "Hiperbilirrubinemia" and "Fototerapia" and "Enfermagem". Na Tabela I descrevemos o caminho percorrido.

A terceira etapa consistiu na seleção dos trabalhos científicos de acordo com seus conceitos embasadores, objetivos e metodologia, a definição das informaçóes a serem extraídas dos artigos científicos selecionados e categorizaçáo dos mesmos.

Como quarta etapa, realizamos a avaliação dos estudos incluídos na revisão integrativa e análise crítica, correlacionando-os.

$\mathrm{Na}$ quinta etapa foi realizada a interpretação e discussão dos resultados, destacando os trabalhos que trouxeram de forma mais clara e concisa as diferenças conceituais entre as vertentes que foram pesquisadas.

\section{Resultados}

Segundo a tabela, classificamos os artigos apresentados de acordo com os conceitos trazidos por cada autor, dos quais surgiram dois eixos temáticos para discussão: Sentimentos maternos: meu filho sob uma luz; e a Comunicação entre a enfermagem e as mães: componente essencial da assistência.

\section{Discussão}

\section{Sentimentos maternos: meu filho sob uma luz}

A realidade de presenciar um filho em fototerapia, o que para a equipe de enfermagem e demais envolvidos indiretamente pode parecer algo simples que ocorre ocasionalmente numa rotina neonatal, para uma mãe pode ser assustador observar seu filho num ambiente desconhecido, sob uma luz com olhos vendados e isso na maioria das vezes é devido à dificuldade de esclarecimento sobre os detalhes do tratamento que consequentemente causam sentimentos de tristeza, inquietação, entre outros.

Nesta perspectiva, as experiências relatadas pelas mães que experimentam pela primeira vez seu filho sob fototerapia é surpreendente, pois ao adentrar a primeira vez na UTIN, um ambiente estranho e assustador, a mãe pode ser tomada por vários sentimentos. Essas primeiras experiências vivenciadas pelas mães evidenciam um preocupação com o seus filhos, apesar de não ser primíparas, experiência pelo qual passaram pela primeira vez, tornando-se nova e inesperada [5].

A maioria das vezes, as mães por se sentirem tímidas e/ou temerosas, não sabem a quem se dirigir para dirimir suas dúvidas e anseios e isto faz com que seu imaginário atribua ao tratamento improváveis riscos futuros. Para a mãe que não espera ver um filho internado em uma UTIN e ainda desconhece os riscos e os benefícios do tratamento, presenciar esse fato pela primeira vez é preocupante.

Tabela I - Fluxograma do caminho percorrido.

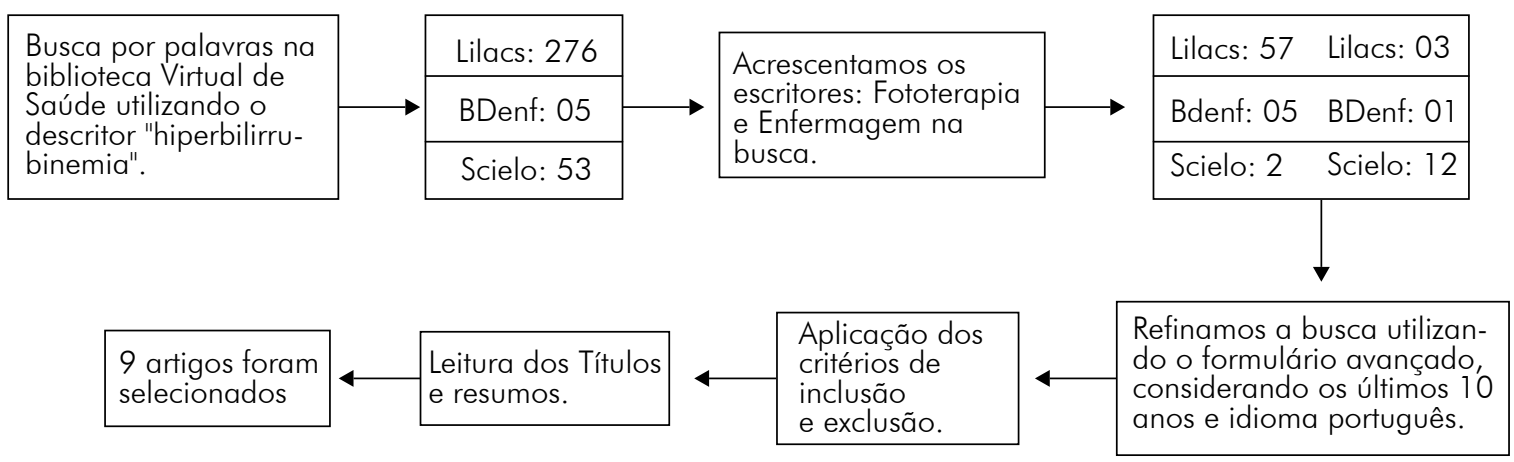


Tabela II - Artigos selecionados e sistematizados.

\begin{tabular}{|c|c|c|c|}
\hline Título & Periódico & $\begin{array}{l}\text { Base de } \\
\text { Dados }\end{array}$ & Principais Resultados \\
\hline $\begin{array}{l}\text { Tecno- } \\
\text { logia } \\
\text { educati- } \\
\text { va para } \\
\text { a prática } \\
\text { do cui- } \\
\text { dado de } \\
\text { enferma- } \\
\text { gem com } \\
\text { mães de } \\
\text { neonatos } \\
\text { sob foto- } \\
\text { terapia. }\end{array}$ & \begin{tabular}{|l} 
Texto \& Contexto \\
- Enfermagem
\end{tabular} & SciELO & $\begin{array}{l}\text { Para os profissionais da equipe de saúde, iniciar a fototerapia em um } \\
\text { neonato na UIN é um procedimento terapêutico bastante comum, pois } \\
\text { faz parte das rotinas às quais já estão afeiçoados. Para a mãe, entretan- } \\
\text { to, que não conhece o tratamento ou nem sequer sabe o porquê da sua } \\
\text { utilização e vivencia pela primeira vez um filho sob fototerapia, qual será } \\
\text { este significado? Nesse contexto, é imprescindível que a equipe de saúde } \\
\text { esteja disponível para acolher os pais, incentivar a presença de familiares, } \\
\text { além de lhes prestar os devidos esclarecimentos sobre o estado de saúde } \\
\text { do neonato. }\end{array}$ \\
\hline $\begin{array}{l}\text { Enferma- } \\
\text { gem e o } \\
\text { cuidado } \\
\text { huma- } \\
\text { nístico: } \\
\text { proposta } \\
\text { de inter- } \\
\text { venção } \\
\text { para a } \\
\text { mãe do } \\
\text { neonato } \\
\text { sob foto- } \\
\text { terapia. }\end{array}$ & $\begin{array}{l}\text { Ciencia y Enfer- } \\
\text { mería XII }\end{array}$ & SciELO & $\begin{array}{l}\text { Enfatizamos aqui a importância da comunicação entre a equipe de saúde } \\
\text { e os familiares do RN com vistas ao esclarecimento de dúvidas e repas- } \\
\text { se de informações verdadeiras, atualizadas e em linguagem adequada } \\
\text { ao nível de compreensão dos pais. Ademais, deve haver o respeito às } \\
\text { suas crenças e valores, para que se sintam apoiados, valorizados e não } \\
\text { venham a se afastar da UIN e, consequentemente, do seu filho nesse } \\
\text { período crucial e significativo. } \\
\text { Desse modo entendemos ser preciso estabelecer um canal de comuni- } \\
\text { cação de forma mais efetiva com a mãe e a família do RN em uso de } \\
\text { fototerapia }\end{array}$ \\
\hline $\begin{array}{l}\text { Percep- } \\
\text { ções } \\
\text { maternas } \\
\text { sobre o } \\
\text { neonato } \\
\text { em uso } \\
\text { de foto- } \\
\text { terapia. }\end{array}$ & $\begin{array}{l}\text { Esc Anna Nery } \\
\text { Rev Enferm }\end{array}$ & SciELO & $\begin{array}{l}\text { A equipe de enfermagem atenta, preparada e competente está sempre } \\
\text { pronta para atender a mãe e o neonato. Percebemos sentimentos de preo- } \\
\text { cupação, de insegurança emocional e de temor, aliados ao sentimento } \\
\text { maternal de amor pelo filho e até de tristeza, por todos os momentos que } \\
\text { estão passando junto a eles. Entendemos todo o seu sofrimento, principal- } \\
\text { mente ao ver o quadro apresentado, isto é, o aparelho de fototerapia, o } \\
\text { bebê com a venda escura nos olhos, a luz e, principalmente, a distância } \\
\text { do aconchego dos braços da mãe. Dessa forma, evidencia-se a necessi- } \\
\text { dade de maiores esclarecimentos e informações sobre o referido trata- } \\
\text { mento. }\end{array}$ \\
\hline $\begin{array}{l}\text { O neo- } \\
\text { nato sob } \\
\text { fotote- } \\
\text { rapia na } \\
\text { unidade } \\
\text { de inter- } \\
\text { nação } \\
\text { neonatal } \\
\text { - conhe- } \\
\text { cimento } \\
\text { das } \\
\text { mães. }\end{array}$ & Rev. RENE & LILACS & $\begin{array}{l}\text { A comunicação mãe-filho, iniciada na fase intraútero, intensifica-se nos } \\
\text { primeiros meses de vida, a partir dos afetos, atuando como um elo entre o } \\
\text { bebê e a mãe. As expressões de afeto são as primeiras formas de lingua- } \\
\text { gem. } \\
\text { Evidencia-se, portanto, a importância de estabelecer-se uma relação de } \\
\text { empatia e confiança com os familiares, para que se obtenha resultado fa- } \\
\text { vorável o mais rápido possível. Afinal, compreende-se melhor aquilo que } \\
\text { se compartilha, e assistir o neonato na perspectiva do cuidado à família, } \\
\text { que tem potencial de transformação, será um grande passo na evolução } \\
\text { da enfermagem neonatal, considerando que orientar não é depositar } \\
\text { informações, mas discutir com o outro as inúmeras possibilidades do que } \\
\text { pode ser feito. }\end{array}$ \\
\hline
\end{tabular}




\begin{tabular}{|c|c|c|c|}
\hline Título & Periódico & $\begin{array}{c}\text { Base de } \\
\text { Dados }\end{array}$ & Principais Resultados \\
\hline $\begin{array}{l}\text { Rev } \\
\text { Gaúcha } \\
\text { Enferm }\end{array}$ & $\begin{array}{l}\text { Crenças e senti- } \\
\text { mento vivencia- } \\
\text { dos pelas mães } \\
\text { do recém-nascido } \\
\text { sob fototerapia }\end{array}$ & LILACS & $\begin{array}{l}\text { Todo sentimento, quer seja positivo ou negativo, vem sempre acompa- } \\
\text { nhado de crenças positivas ou negativas. Questões como amor, angús- } \\
\text { tia, ansiedade, próprias da existência humana não podem ser tratadas } \\
\text { como fatos, números e percentuais. Por isso, é preciso um novo modo de } \\
\text { olhar para essas questões, um olhar compreensivo: ver o homem como } \\
\text { sujeito e não como objeto. Supomos que o medo seja decorrente da falta } \\
\text { de informação acerca das causas que levaram o RN àquele tratamento } \\
\text { e, portanto, ao medo de perder o filho; a tristeza fica, certamente, por } \\
\text { conta do estado de solidão do bebê, exposto à luz artificial e ao aparato } \\
\text { técnico. Acreditamos que o medo do desconhecido, medo da perda do } \\
\text { filho aliado ao sentimento de tristeza pelo estado de isolamento do bebê } \\
\text { e, até mesmo, sentimento de culpa, levam a mãe ao desalento e ao choro } \\
\text { muitas vezes contido. }\end{array}$ \\
\hline $\begin{array}{l}\text { Revista } \\
\text { Latino } \\
\text { America- } \\
\text { na de } \\
\text { Enferma- } \\
\text { gem }\end{array}$ & $\begin{array}{l}\text { O recém-nascido } \\
\text { sob fototerapia: } \\
\text { A percepção da } \\
\text { Mãe }\end{array}$ & LILACS & $\begin{array}{l}\text { Quando mãe e bebê ficam juntos, após o nascimento, inicia-se uma série } \\
\text { de eventos sensoriais, hormonais, fisiológicos, imunológicos e compor- } \\
\text { tamentais, muitos dos quais contribuem positivamente para a ligação } \\
\text { do binômio mãe-filho. Essas reações manifestadas pelos pais, ainda } \\
\text { mais exacerbadas nas mães, sempre nos inquietaram, por imaginarmos } \\
\text { que, sendo a fototerapia um procedimento não invasivo, não justificava } \\
\text { tamanho sofrimento. O ato do cuidar humanístico revela-se não apenas } \\
\text { emocionalmente, mas concretamente. A enfermeira, embasada na sua } \\
\text { competência técnica, sem perder a ternura, deve munir-se de docilidade } \\
\text { e buscar transmitir à mãe as informações que necessita saber para se } \\
\text { tranquilizar. }\end{array}$ \\
\hline $\begin{array}{l}\text { Rev. } \\
\text { Rene. } \\
\text { Fortaleza }\end{array}$ & $\begin{array}{l}\text { Comunicação: } \\
\text { Instrumento } \\
\text { básico da en- } \\
\text { fermagem para } \\
\text { cuidar da mãe } \\
\text { do neonato sob } \\
\text { fototerapia }\end{array}$ & LILACS & $\begin{array}{l}\text { Para a mãe que vivencia pela primeira vez um filho sob fototerapia essa } \\
\text { visão pode parecer assustadora, conforme sua percepção em relação } \\
\text { ao tratamento, seus riscos e benefícios. Dessa forma, é fundamental se } \\
\text { estabelecer o processo de comunicação da equipe de saúde com a mãe } \\
\text { no intuito de esclarecê-la devidamente a respeito da terapêutica à qual } \\
\text { seu filho é submetido. }\end{array}$ \\
\hline $\begin{array}{l}\text { Revista } \\
\text { Interdis- } \\
\text { ciplinar } \\
\text { NOVA- } \\
\text { FAPI }\end{array}$ & $\begin{array}{l}\text { O conhecimen- } \\
\text { to das mães de } \\
\text { recém-nascidos } \\
\text { com icterícia } \\
\text { neonatal sobre o } \\
\text { tratamento fotote- } \\
\text { rápico. }\end{array}$ & LILACS & $\begin{array}{l}\text { Constatou-se o déficit de conhecimento das mães sobre a terapêutica } \\
\text { e seus cuidados. A comunicação apresenta-se como um instrumento } \\
\text { indispensável na construção do conhecimento materno, destacando-se a } \\
\text { importância do papel da enfermagem responsável pela instalação, manu- } \\
\text { tenção e pelo sucesso do tratamento. }\end{array}$ \\
\hline $\begin{array}{l}\text { Revista } \\
\text { de Enfer- } \\
\text { magem }\end{array}$ & $\begin{array}{l}\text { Ações educativas } \\
\text { de assistência de } \\
\text { enfermagem em } \\
\text { ambiente hospi- } \\
\text { talar: a atenção a } \\
\text { pais e familiares } \\
\text { de neonatos em } \\
\text { fototerapia. }\end{array}$ & LILACS & $\begin{array}{l}\text { A educação em saúde é compreendida hoje como uma importante ferra- } \\
\text { menta para a transformação do fazer dos profissionais dessa área, bem } \\
\text { como, para a transformação das realidades vivenciadas. Ela, quando } \\
\text { trabalhada de forma a compartilhar a responsabilidade pelo cuidado, } \\
\text { pode transformar as ações mais técnicas desenvolvidas em ambientes } \\
\text { mais tradicionais, como o hospital, em ações mais humanizadas, onde } \\
\text { o vínculo e o respeito pelo saber do outro se realizam de forma cíclica e } \\
\text { horizontalizada. }\end{array}$ \\
\hline
\end{tabular}


No âmbito de uma Unidade de Internação Neonatal têm lhe permitido observar que as mães ao adentrarem a unidade para visitar os filhos recém-nascidos e se depararem com o bebê sob uma intensa luminosidade, olhos ocluídos pelo protetor ocular (ritual fototerápico) externam alguns comportamentos tais como a relutância em tocar no seu filho, enquanto outras náo pedem informaçóes sobre o tratamento ou sobre seu estado de saúde, e algumas não conseguem reprimir o pranto e se expressam por lágrimas [5]. O simples fato de não serem convenientemente informadas origina sentimentos de desencanto, conformismo e incompreensão do quadro clínico do bebê. As preocupaçóes durante a hospitalização são muitas, os pais ficam confusos, querem entender a patologia do $\mathrm{RN}$, porém temem pelo pior e sofrem tanto na dúvida quanto na certeza.

Os sentimentos de preocupação, de insegurança emocional e de temor, aliados ao sentimento maternal de amor pelo filho e até de tristeza, por todos os momentos que estáo passando junto a eles. Nesse sentido as mães ficam muito apreensivas, com dúvidas e chorosas por causa do sofrimento do seu filho $[8,9]$.

O pânico ou desolamento das mães ao verem seus filhos com os olhos vedados durante a fototerapia, o medo do desconhecido, manifesto muitas vezes por lágrimas furtivas, ou mesmo, copiosas, de algumas mães, faz parte do cenário. Esse medo decorrente da falta de informaçáo acerca das causas que levaram o $\mathrm{RN}$ aquele tratamento e, portanto, ao medo de perder o filho; a tristeza fica, certamente, por conta do estado de solidáo, exposto à luz artificial e ao aparato técnico. Acreditam que o medo do desconhecido, medo da perda do filho aliado ao sentimento de tristeza pelo estado de isolamento e, até mesmo, sentimento de culpa, levam a mãe ao desalento e ao choro muitas vezes contido [10].

Ressalta-se que as mães saíam da UTIN sem sequer tocar o bebê e outras não pediam informaçóes sobre o tratamento, ou o estado de saúde do filho, enquanto algumas permitiam que lágrimas furtivas deslizassem por suas faces ou não conseguiam conter o choro. As máes podem apresentar alteraçóes comportamentais em relação à fototerapia, ver o filho em fototerapia pode ser extremamente perturbador para a mãe, particularmente pela oclusão ocular interferindo no processo de ligação da díade máe-filho, quebrando o vínculo e gerando ansiedade. As expressóes revelaram o temor e a preocupaçáo relacionados à possibilidade de seus filhos estarem cegos ou virem a apresentar algum problema dessa natureza no que se refere à visão [11].

Consonante, realçamos que o déficit de conhecimento poderia ser sanado com uma assistência individual e humanizada, focando náo apenas o cuidado, mas também o sofrimento vivenciado pelas mães.

Portanto, a carência de informaçóes, de atenção, de acolhimento, da presença autêntica e da comunicaçáo efetiva por parte dos profissionais da equipe de saúde é favorável e consequente isolamento, insegurança e sentimentos por parte da máe [12]. Os sentimentos manifestos e as inquietaçóes são oriundos do desconhecimento do tratamento, seus riscos e benefícios, e da patologia em si, a qual, por sua vez, dimensiona-se em consequência da falha e/ou ausência na comunicação dos profissionais da equipe de saúde com as máes dos $\mathrm{RN}$ sob fototerapia.

Contudo há de se destacar a suprema importância de estarmos como profissionais de enfermagem, reconhecendo o quanto as máes que têm seu filho sobre este tratamento têm naturalmente suas dúvidas e sentimentos que devem ser considerados.

É perceptível o sofrimento de muitos pais, causado pelo afastamento simbólico e temporário do filho, em especial pela ausência do contato visual, ou seja, olho a olho, pois estes estão com a proteção ocular. Assim sendo, é importante a presença do profissional enfermeiro para acompanhar os pais, informando-lhes e tirando-lhes dúvidas de forma clara, e respeitosa aos seus conhecimentos e vivências já acumuladas [13].

Destacamos que os pais merecem total respeito, pois a maneira que os tratamos influencia diretamente na eficácia do tratamento, uma vez que o $\mathrm{RN}$ de certa forma percebe quando o ambiente não lhe é agradável, isto se dá devido ao laço que o une aos seus pais. Lembrando que uma assistência quando feita integralmente não deve ser focalizada somente na patologia ou no tratamento, mas em todos os outros fatores que envolvem a vida do paciente e um dos principais destes é a família que neste âmbito deve receber de nossa parte um cuidado especial.

\section{Comunicaçáo entre a enfermagem e as mães: componente essencial da assistência}

Entendemos que a comunicação com as mães de neonatos sob fototerapia se manifesta como um 
fator imprescindível no tratamento, pelo fato de que quando esta comunicação é eficaz, a mãe se sente segura e valorizada e consequentemente isto reflete na recuperação de seu filho.

É fundamental se estabelecer a comunicação da equipe de saúde com a mãe, com a finalidade de esclarecê-la devidamente a respeito da terapêutica a qual seu filho é submetido. A presença autêntica, a escuta atentiva, o estar com a máe nos encontros individuais e nas unidades de internação foram pontos decisivos na relação interpessoal da tríade enfermeira-mãe-recém-nascido [5]. Diante do contexto vivido, o diálogo da enfermeira com as mães dos neonatos sob fototerapia, como o suporte de tecnologia educativa para estabelecer a comunicação, são instrumentos disponíveis à enfermagem para implementar a humanização do cuidado.

Desse modo, implementando o direito dos pais de serem informados sobre o diagnóstico e tratamento dos seus filhos e a equipe de saúde deve promover maior aproximação com essas máes, a fim de amenizar a primeira impressão e também incentivar o vínculo mãe-filho.

Devemos ressaltar que a comunicação deve ser praticada em linguagem clara e acessível ao nível cultural e de conhecimento da máe para que ela possa compreender com facilidade. Com base nos problemas identificados, buscaram por meio do diálogo, orientar a mãe e responder às suas indagaçóes e dúvidas existentes. Perceberam que todas as máes necessitam de um apoio indispensável para a compreensão desse momento em que vivenciam o $\mathrm{RN}$ em uso da fototerapia [14]. Julgaram necessário informar os pais convenientemente tanto a respeito do quadro clínico do $\mathrm{RN}$ como de todos os procedimentos realizados e equipamentos empregados para a estabilização e manutenção da saúde e da vida do seu filho, pois o uso destes pode comprometer a interação da criança com seus pais. Ademais, deve haver o respeito às suas crenças e valores, para que se sintam apoiados, valorizados e não venham a se afastar da UTIN e, consequentemente, do seu filho nesse período crucial e significativo.

Essas práticas concernem aos profissionais de enfermagem vislumbrar uma nova caminhada, lembrando-se da importância das orientaçóes durante o pré-natal sobre o tema em foco [8]. Portanto, surge a necessidade de desenvolver novas formas de assistência, buscando a compreensão de cada mãe, além de repensar os ensinamentos e orientaçóes para que possamos, finalmente, assumir autenticamente os cuidados de enfermagem ao binômio mãe-filho no sentido de proporcionar melhor qualidade da assistência.

A orientação destas mães, que estão sendo acompanhadas diariamente pela equipe de saúde, pode influenciar na eficácia do tratamento do mesmo. A desinformação a respeito da modalidade terapêutica pode contribuir para alimentar o medo e a insegurança dessas mães. $\mathrm{O}$ ato do cuidar humanístico revela-se não apenas emocionalmente, mas concretamente. A enfermeira, embasada na sua competência técnica, sem perder a ternura, deve munir-se de docilidade e buscar transmitir à mãe as informaçóes que necessita saber para se tranquilizar.

Vale destacar que as mães vivem as dificuldades em aprender o porquê do tratamento, os jargóes técnicos, muitas vezes utilizados pela equipe de saúde e a necessidade de tocar o bebê, que não é incentivada e até cerceada pela equipe, gerando a incompreensão do tratamento e da patologia, o que torna evidente a falha de comunicação entre a equipe de saúde e as máes [15].

Diante da falta de conhecimento da máe a respeito da terapêutica e dos cuidados relacionados a ela, compete ao enfermeiro, como profissional que detém conhecimento científico, orientá-la sobre os cuidados que devem ser prestados ao $\mathrm{RN}$, esclarecendo suas dúvidas e mostrando-se disponível para ajudá-la diante das dificuldades. É necessário estabelecer um vínculo afetivo de confiança e cumplicidade entre o profissional e o cliente [16].

$O$ profissional enfermeiro deve utilizar uma linguagem de fácil entendimento, para que os familiares náo se sintam constrangidos, favorecendo a compreensão do assunto, estimulando assim o surgimento de possíveis questionamentos e a exteriorização de dúvidas, medos e ansiedades [13].

A interação enfermeiro-cliente é imprescindível. Assim, a comunicação apresenta-se como um instrumento relevante na atividade de enfermagem, além de propiciar o estabelecimento de um relacionamento efetivo. Assim, diante do contexto vivido, propomos uma assistência de enfermagem baseada em uma comunicação efetiva com o intuito de implementar a humanização do cuidado, além de proporcionar a valorização do enfermeiro diante da equipe de saúde e a clientela assistida [16].

Diante da ocorrência de possíveis sequelas ou intercorrências que podem acontecer durante o tratamento é indispensável que o profissional oriente, apoie e essencialmente informe de maneira clara e 
objetiva, para que tudo se desenvolva da melhor maneira possível. A equipe de enfermagem são os profissionais que recebem e preparam o recém-nascido para o tratamento, bem como, preparam os equipamentos que serão utilizados para a fototerapia, como os focos de luz, as incubadoras, etc. Dentre esses cuidados, destacam-se a proteção ocular dos recém-nascidos, a distância e o posicionamento da fonte luminosa do neonato, os cuidados com higiene e quanto à prevençấo de queimaduras etc. [13].

Enfim, entendemos a importância do proceder da equipe de enfermagem com as mães de RN sob fototerapia, ou seja, a comunicação é um fator fundamental para que elas compreendam todo o procedimento o qual seu filho está sendo submetido naquele momento.

\section{Conclusão}

A realidade dos ambientes nas UTIN está muito distante de ser o adequado para as necessidades das mães de neonatos sob fototerapia, por isso utilizamos este estudo focalizando na atuação humanística do enfermeiro neste processo.

Relatamos sobre os sentimentos maternos que devem ser de extrema importância, como profissionais de enfermagem, sempre tendo um olhar holístico e lembrando que a família é um dos principais fatores para o sucesso no tratamento tanto para o bebê como para a mãe.

Discorremos também sobre a forma como o enfermeiro interage com a mãe, ou seja, a comunicação utilizada. O enfermeiro deve prestar uma assistência integral no sentido de informar a mãe sobre o tratamento a que seu filho está sendo submetido e tirar todas as dúvidas existentes.

Portanto, a assistência da enfermagem prestada às mães de neonato sob fototerapia, envolvendo o diálogo, a sensibilidade no cuidar, a presença autêntica, junto ao binômio mãe-filho é fundamental. Contudo, torna-se imprescindível à família uma atuação de forma direta e integral.

É preciso direcionar mais pesquisas para a atenção a essas mães. Pedimos que a equipe de enfermagem esteja atenta para este cuidado que é tão fundamental não só neste tratamento, mas em todos. Nós enfermeiros precisamos nos posicionar e nos preparar cada vez mais.

\section{Referências}

1. Lowdermilk DL, Perry SE, Bobak IM. O cuidado em enfermagem maternal. 5a ed. Porto Alegre: Artmed; 2002.

2. Wong DL. Enfermagem Pediátrica: elementos essenciais à intervenção efetiva. 5a ed. Rio de Janeiro: Guanabara Koogan; 1999.

3. Schmitz EMR. A Enfermagem em Pediatria e Puericultura. São Paulo: Atheneu; 2005.

4. Harrison TR. Medicina interna. 18a ed. Rio de Janeiro: McGrawHill; 2013.

5. Campos ACS, Cardoso MVLML. Tecnologia educativa para a prática do cuidado de enfermagem com mães de neonatos sob fototerapia. Texto Contexto Enferm 2008;17(1):36-44.

6. Pompeo DA, Rossi LA, Galvão CM. Revisão integrativa: etapa inicial do processo de validação do diagnóstico de enfermagem. Acta Paul Enferm 2009;22(4):434-8.

7. Gil AC. Como elaborar projetos de pesquisa. $4 \mathrm{a}$ ed. São Paulo: Atlas; 2002.

8. Rodrigues FLS, Silveira IP, Campos ACS. Percepções maternas sobre o neonato em uso de fototerapia. Esc Anna Nery Rev Enferm 2007;11(1):86-91.

9. Pinheiro GR, Ximenes LB, Dodt RCM, Oriá MOB, Barbosa RCM. O neonato sob fototerapia na unidade de internação neonatal - conhecimento das máes. Rev RENE 2007;8(3):44-51.

10. Campos ACS, Leitão GCM. Crenças e sentimentos vivenciados pelas mães de recém-nascidos sob fototerapia. Rev Gaúcha Enferm 2005;26(1):50-56.

11. Campos ACS, Cardoso MVLML. O recém-nascido sob fototerapia: A percepção da Mãe. Rev Latinoam Enferm 2004;12(4):606-13.

12. Campos ACS. Comunicação com mães de neonatos sob fototerapia: Pressupostos humanísticos. Rev RENE 2007;8(3):126-8.

13. Rosa J, Faccin C, Delegrave D, Argenta C, Fransciscatto LHG. Açôes educativas de assistência de enfermagem em ambiente hospitalar: a atenção a pais e familiares de neonatos em fototerapia. Rev Enferm 2012;8(8):154-65.

14. Campos ACS, Cardoso MVLML. Enfermagem e o cuidado humanístico: proposta de intervenção para a mãe do neonato sob fototerapia. Cienc Enferm 2006;12(1):73-81.

15. Campos ACS, Cardoso MVLM. Pagliuca LMF, Rossi LA. Comunicação: Instrumento básico da enfermagem para cuidar da máe do neonato sob fototerapia. Rev RENE 2008;9(4): 24-32.

16. Castro PS, Silva SMS, Linhares TRC, Sousa AM. O conhecimento das mães de recém-nascidos com icterícia neonatal sobre o tratamento fototerápico. Revista Interdisciplinar NOVAFAPI 2011;5(1):16-20. 